\title{
Technical Report: Evacuation Proctography (Defecography) A New Seat and Method of Examination
}

\author{
A. Z. GINAI \\ Department of Radiology, University Hospital Rotterdam-Dijkzigt, The Netherlands
}

\begin{abstract}
A new evacuation proctography (defecography) seat and method of examination is described. The seat was constructed in association with the department of biotechnology. It is constructed of perspex and radiographic demonstration of the distal rectum and anal canal region is obtained without distracting artefacts. Ginai, A.Z. (1990). Clinical Radiology 42, 214-216. Technical Report: Evacuation Proctography (Defecography). A New Seat and Method of Examination
\end{abstract}

Defecography, or evacuation proctography (Bartram et $a l ., 1988$ ) has gained in popularity due to the role it plays in the diagnosis of functional abnormalities of the anorectal region. The common indications for the examination are faecal incontinence, constipation, incomplete evacuation and rectal prolapse or perineal pain. Conditions which can be defined more accurately on defecography are internal rectal or recto-anal prolapse, puborectalis dysfunction, rectocoele and abnormal descent of the perineum.

The examination is relatively easy to perform but the major reason for the limited availability of a proctography service is the absence of a suitable device or seat on which to carry out the examination. The basic requirements for an evacuation proctography examination are:

1 A comfortable seat which should have the following features:

(a) The seat should be easily and safely attached to the fluoroscopy table.

(b) The position of the undercouch tube and seat should be adjustable so that the patient is in a comfortable sitting position.

(c) The seat should be made of a transradiant smooth material without any artefacts in the line of the image.

(d) A filter device is necessary to overcome differences in density between the widest part of the pelvis and region below the line of the buttocks (region of the anal canal). This is important in ensuring good visualization of the anal canal and anorectal region and in order to avoid overexposure of other parts of the radiographs.

2 A rapid filming device such as cinematography or video-recording for the dynamic act of evacuation.

3 A suitable contrast medium such as a thick barium paste or semisolid preparation (Mahieu et al., 1984) containing barium sulphate for filling the rectum.

4 Contrast to outline the anal canal as well as the external anal level.

5 In some female patients where a rectocoele is suspected some method of demonstrating the posterior vaginal wall is necessary, such as coating with a barium soaked tampon (Kelvin and Gardner, 1987).

Correspondence to: Dr A. Z. Ginai, Department of Radiology, University Hospital Rotterdam-Dijkzigt, Dr. Molewaterplein 40, 3015 GD Rotterdam, The Netherlands.
Since 1984 we have carried out over 700 examinations; all have been recorded on videotape in addition to spot radiographs.

Initially we carried out defecography in the recumbent position. We subsequently designed a simple seat consist ing of three rubber rings filled with water (Mahieu et al., 1984) stacked one on top of the other (this also acted as a filter device) and then placed on a wooden chair. A plastic bag was used to line the rings for collection of faeces. This chair was fixed to the foot step of the fluoroscopic table for lateral fluoroscopy. This arrangement for positioning the patient was an improvement on the recumbent position as the sitting position is more natural for the examination (Mahieu and Bartram, 1985).

The seat made with two or three rubber rings in this way had certain disadvantages:

1 It was unstable.

2 In obese patients and particularly in those with extensive perineal descent the depth of the seat was inadequate, leading to loss of important information regarding incomplete or complete rectal prolapse.

Bernier et al. (1988) constructed a 'defecography commode' using wood (solid pine) but according to these authors care must be taken to ensure that the wood grain is perpendicular rather than parallel to the X-ray beam. Plywood should be avoided as it may cause multiple distracting artefactual lines on the image.

Various filtration devices have been described such as water bottles or water filled rings and these have certain disadvantages as described above. Tubular metal frames used for absorption of unwanted radiation cause artefacts on the image. Bernier et al. (1988) have used a series of copper filtering devices selected according to the size of the patient.

Because of these difficulties we planned and designed a suitable evacuation proctography seat, commencing in 1986. The device (Fig. 1) was developed locally in conjunction with the Department of Biotechnology of the Erasmus University (total costs in 1987, approximately $£ 1800$ ).

The seat is made almost completely of clear perspex and the layers and connections are joined using tensol cement. The measurements and thickness of the perspex in different parts of the evacuation proctography seat are given in Fig. 2.

The seat is assembled on a baseplate with a foot rest to 


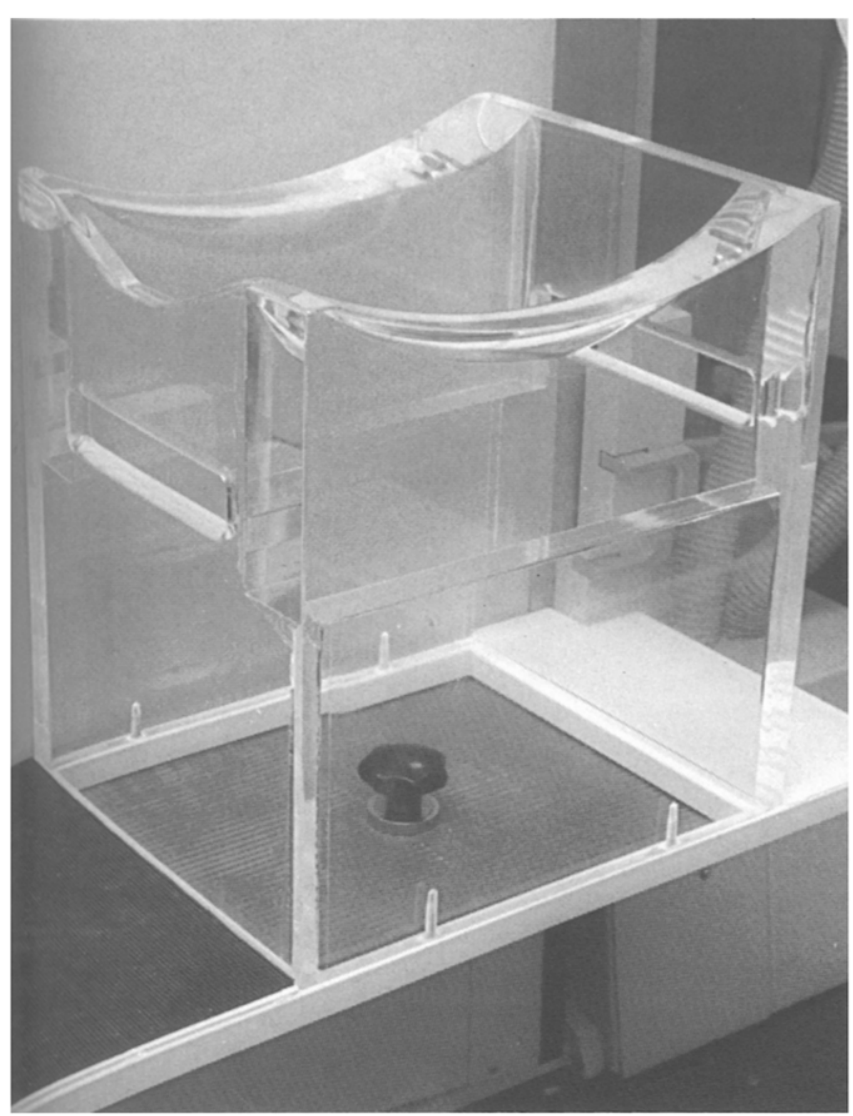

Fig. I - Evacuation proctography (defecography) seat mounted on the fluoroscopic table and fixed with a central screw to the foot rest.

ensure a comfortable sitting position during the examination.

The under surface of the baseplate is fitted with four wheels so that the seat can be wheeled into position and attached onto the foot step (which has a small central hole) of the fluoroscopic table. A large fixing screw passes through the hole in the seat plate and the footstep of the



Fig. 2 - Line drawing of the evacuation proctography seat showing the various measurements in centimetres.

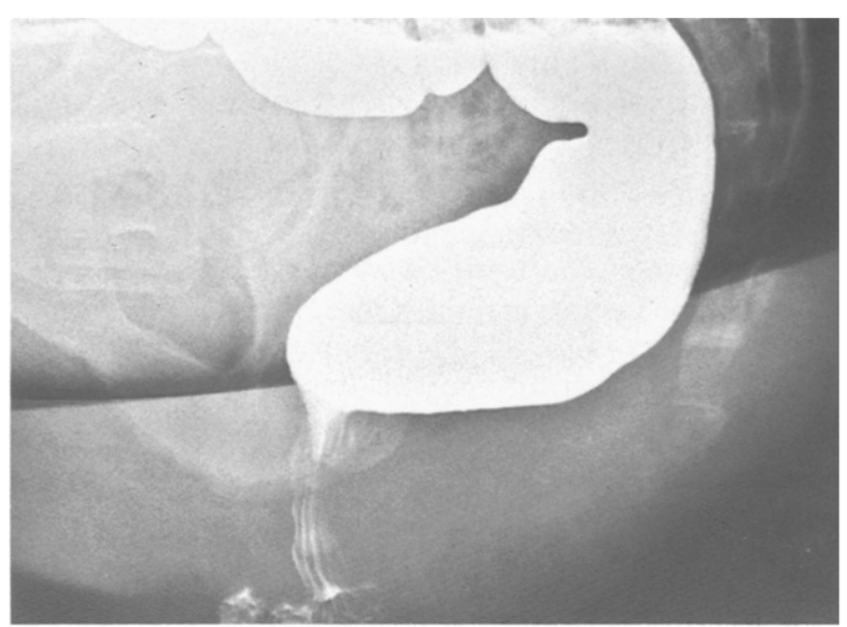

(a)

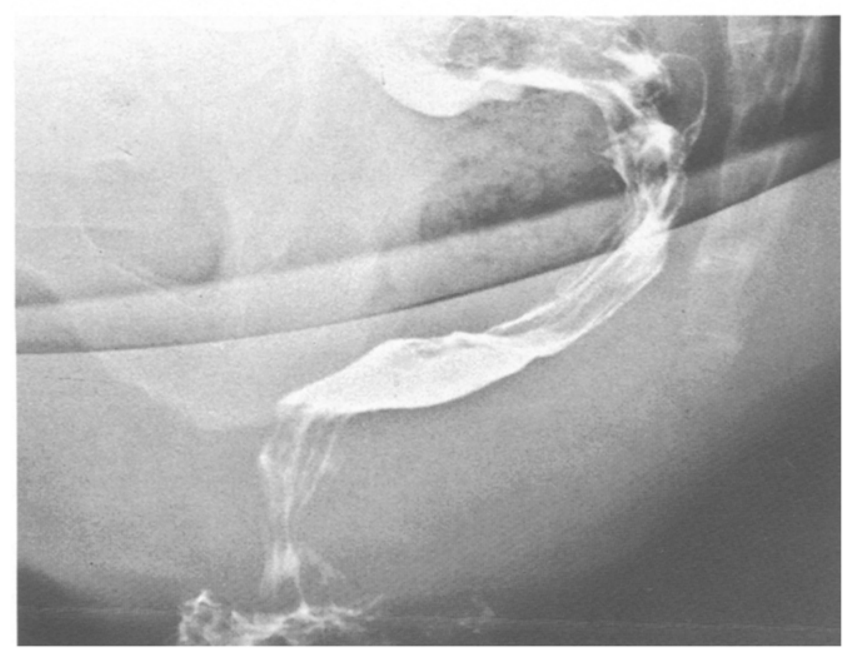

(b)

Fig. $3-(a)$ A filled rectum view at rest in the sitting position. (b) A view at the end of defecation showing perineal descent (as can be noted from the change in position of anorectal region in relation to the ischial tuberosities) and normal evacuation.

fluoroscopic table (Philips diagnost 73 or equivalent fluoroscopic table) giving stable fixation of the seat (Fig. 1).

The advantages of the new evacuation proctography seat are:

1 It is easy to attach the seat to the fluoroscopic table and it is also easily removed after completion of the examinations (in the case of multiple examinations it is not necessary to remove the seat between the examinations). 2 It is a very stable construction and there are no steps for the patient to climb.

3 The material used in the construction of the chair allows a clear fluoroscopic image and good quality videorecording as well as spot radiographs, with no artefacts. The rim of the seat is visible on the images but causes no distraction.

4 The curve of the sides of the seat gives a comfortable position for the patient. No additional devices such as rings are necessary.

5 The thicker perspex layers in the upper parts of the seat act as filter for absorption of unwanted radiation.

6 Large disposable plastic bags are used for collection of faeces. These are easily disposed of at the end of each examination leaving the seat itself clean. 
7 A measuring ruler can be fixed to the centre of the back wall of the seat if required.

8 The seat can be cleaned with soap and water, but stronger detergents discolour the perspex.

We have used the proctography seat since 1988 . The average time for an examination is $15 \mathrm{~min}$.

Our technique consists of filling the rectum with a thick barium sulphate preparation of the type used for a barium enema. We have found this a fairly satisfactory preparation but a trial to compare this thick fluid barium sulphate with a semisolid preparation (as suggested by Mahieu et al. 1984) is being considered. We dip the rectal cannula tip in a thick barium paste before inserting, giving adequate coating and visualization of the anal canal after removal of the cannula.

As the seat is firmly fixed to the X-ray table, the table and patient can be moved into the recumbent position for filling the rectum with barium sulphate under fluoroscopic control. The patient is then taken off the table and the table is moved into the erect position. The patient is then seated for lateral fluoroscopy. The defecography examination is recorded on a video-tape for subsequent review. Spot radiographs (usually two or three) are obtained in the resting position, during defecation and at the end of defecation with the patient still straining (Fig.
3). This last view is important for the evaluation of perineal descent and diagnosis of incomplete internal rectal- or recto-anal prolapse.

Acknowledgements. Thanks are due to Mr F. van der Meer, Physicist in the Department of Radiology and Mr F. Schumacher of the Department of Biotechnology of the Erasmus University, Rotterdam for assistance with the design and construction of the evacuation proctography seat described here.

I would also like to thank Mrs J. de Vos for typing the manuscript and Mr T. Rijsdijk for producing the photographs.

\section{REFERENCES}

Bartram, CI, Turnbull, GK \& Lennard-Jones, JE (1988). Evacuation proctography: An investigation of rectal expulsion in 20 subjects without defecatory disturbance. Gastrointestinal Radiology, 13, 7280 .

Bernier, P, Sevenson, GW \& Shorvon, P (1988). Defecography commode. Radiology, 166, 891-892.

Kelvin, FM \& Gardiner, R (1987). Clinical imaging of the colon and rectum, pp. 49. Raven Press, New York.

Mahieu, PHG, Pringot, J \& Bodart, P (1984). Defecography I: Description of a new procedure and results in normal patients. Gastrointestinal Radiology, 9, 247-251.

Mahieu, PHG \& Bartram, CI (1985) Apport de la radiographie a l'étude des troubles de la défécation. Acta Gastro-enterologica Belgica, 48, 11. 